\title{
Origin and Development of the Precursor Lesions in Experimental Pancreatic Cancer in Rats
}

\author{
Dale E. Bockman, Junchao Guo, Peter Büchler, Michael W. Müller, \\ Frank Bergmann, and Helmut Friess \\ Departments of General Surgery (DEB, JG, PB, MWM, HF) and Pathology (FB), University of Heidelberg, Germany
}

\begin{abstract}
SUMMARY: Notwithstanding the importance of understanding how pancreatic ductal adenocarcinoma develops, the process remains controversial. A key question is whether the cells of origin of the tubular complexes that constitute precursor lesions are derived from a single cell type or from multiple types. Suggestions that they arise solely from centroacinar cells or ductal cells have been based on inference due to their morphologic appearance in tissue from patients or investigation of limited numbers of tubular complexes in animal models later in the carcinogenic process. The present study establishes clearly that two steps are involved; rapid transdifferentiation to produce tubular complexes followed later by transformation of the component cells. Animals were killed at intervals beginning 1 day after implantation of the carcinogen dimethylbenzanthracene. Transdifferentiation of acinar cells to ductal cells does not require cell division. Transition of lobules to tubular complexes begins by 2 days after implantation of carcinogen. Within 4 days after implantation well-developed tubular complexes are present. Islets participate in the process. Ductal adenocarcinoma is observed by 1 month after implantation of carcinogen. Chymotrypsin and cytokeratin localized by immunocytochemistry indicate acinar and ductal cell characteristics. Acino-ductal transdifferentiation persists in carcinogen-implanted animals, but not in controls implanted with sodium chloride crystals or subjected to sham implantation. The precursor lesions (tubular complexes) are formed by the transdifferentiation of acinar cells and to a lesser extent islet cells, with the incorporation of the duct cells pre-existing in the lobules. Therefore, cells that at one time were acinar cells, islet cells, and duct cells, provide the precursor cells for the ductal adenocarcinoma that develops from tubular complexes. The results raise the question whether the transdifferentiated cells in the tubular complexes of patients with chronic pancreatitis are more susceptible to carcinogenic influences, resulting in the increased rate of pancreatic cancer. (Lab Invest 2003, 83:853-859).
\end{abstract}

$W$ ell-differentiated pancreatic ductal adenocarcinoma is composed of cells that have the morphology and markers of duct cells. It has seemed a reasonable assumption, therefore, that in the absence of the capability to study the earliest changes leading to pancreatic adenocarcinoma in humans, the cancer arises exclusively from pancreatic ducts.

A procedure for inducing cancer that resembles human pancreatic ductal adenocarcinoma has been well established (Bockman et al, 1976; Dissin et al, 1975; Rivera et al, 1997). It involves the implantation of a carcinogen, dimethylbenzanthracene (DMBA), into the pancreas of rats. Ductal adenocarcinoma develops in a significant proportion of the recipients over a period of months. Earlier reports were based on ob-

\section{DOI: 10.1097/01.LAB.0000074918.31303.5A}

Received March 4, 2003.

The first two authors contributed equally to this manuscript. Junchao Guo worked as a clinical research fellow in the Department of General Surgery, Peking Union Medical College Hospital, Chinese Academy of Medical Science, and Peking Union Medical College, Beijing, China. Dale E. Bockman, Professor and Chairman Emeritus, Department of Cellular Biology and Anatomy, Medical College of Georgia, Augusta, was a guest professor at the University of Heidelberg, Germany.

Address reprint requests to: Dr. Helmut Friess, Department of General Surgery, University of Heidelberg, Im Neuenheimer Feld 110, 69120 Heidelberg, Germany servations from specimens harvested several months after implantation (Bockman et al, 1976; Dissin et al, 1975; Rivera et al, 1997). A more recent study included tissue taken as soon as 2 weeks after implantation (Jimenez et al, 1999). In these animals there is the presence in the pancreas of complex arrangements of duct-like cells, called tubular complexes, especially prominent close to the implantation site.

Tubular complexes have been considered precursor lesions of adenocarcinoma produced by implantation of DMBA into the rat pancreas (Jimenez et al, 1999). In time ductular hyperplasia and carcinoma in situ develop in tubular complexes. Adenocarcinomas were reported months later (Jimenez et al, 1999).

Overexpression of transforming growth factor- $\alpha$ (TGF- $\alpha$ ) in transgenic mice induces the formation of tubular complexes in the pancreas (Bockman and Merlino, 1992; Sandgren et al, 1990). Wagner et al (Wagner et al 1998, 2001) have identified malignant tumors originating from tubular complexes in mice overexpressing TGF- $\alpha$. The mice developed dysplastic tubular complexes, some of which showed malignant progression within these foci. Transformed cells developed from duct-like cells within the tubular complexes. The tubular complexes were considered premalignant lesions, precursors of invasive carcinoma. An acinar-ductalcarcinoma sequence is described that reflects genetic alterations of the human disease (Wagner et al, 2001). 
Because tubular complexes may serve as preneoplastic lesions, it is of interest to know how they originate. An early study, based on observations 1 to 13 months after implantation of DMBA, led to the conclusion that the tubular complexes resulted from dedifferentiation of acinar cells, ie, that acinar cells lost zymogen granules and eventually took on the characteristics of ductular cells, thus contributing to the pool of cells from which cancer could originate (Bockman et al, 1978). A more recent study, based on observations 2 weeks to 9 months after implantation of DMBA, led to the suggestion that the origin of pancreatic adenocarcinoma was solely from ductal cells (Jimenez et al, 1999). In the latter study, cells in tubular complexes 2 weeks and 1 month after implantation were described as uniformly expressing cytokeratin, a ductal marker, with none expressing chymotrypsin, a marker for acinar cells.

The current study was designed to examine the formation of tubular complexes during the first days after implantation of DMBA and to follow the subsequent development of these precursor lesions. The results support the participation of acinar cells, which transdifferentiate and become part of the tubular complexes, therefore becoming potential precursors of adenocarcinoma.

\section{Results}

\section{Rapid Production of Tubular Complexes}

The implantation process caused tissue damage to the pancreas in the region of the DMBA and sutures. Examination of the tissue 1 day after implantation (Fig. $1 \mathrm{~A})$ revealed extensive edema with separation of acini, predominantly acute inflammatory infiltrate, and cell death due to necrosis and apoptosis. The extracellular matrix was extensive, but the cellular and fibrous elements were sparse. The lobular architecture was maintained albeit altered.

By 2 days after implantation, it was possible to detect the beginning transition of acini (Fig. 1B). The lumen was enlarged in some acini. The localization of chymotrypsin in the cells forming the periphery of these structures (Fig. 1B) indicated they were acinar cells that retained zymogen.

At 4 days (Fig. 1, C to F), formation of tubular complexes was quite obvious. Well-developed tubular complexes arranged like pancreatic lobules were present in some areas (Fig. 1C). The process of formation of tubular complexes continued, as evidenced by lobules in transition from mostly acinar cells to accumulations of tubules (Fig. 1D). Most well developed tubular complexes were composed of cells that had only the marker for duct cells even when double-stained for chymotrypsin and cytokeratin (Fig. 1E). As the transition from acini to tubules progressed, there was a tendency for the lumen to enlarge and for the wall to thin. To a lesser extent than acini, islets participated in the transition to tubular structures (Fig. 1F).

\section{Transformation to Adenocarcinoma}

Further changes in tubular complexes were focal. Thinning of the tubular wall became extreme in some places. Fusion of tubules produced less complex structures with larger lumens. Tubules showed elongated epithelial cells (Fig. 2A) and multiple-layered walls (Fig. 2B). Papillae projected into enlarged lumens (Fig. 2C). Mitotic figures became obvious in some of the regions containing proliferating cells (Fig. 2, B and C), whereas they were scarce or nonexistent earlier. An alternate change was the loss of regular arrangement of the tubules, with distortion of cells, the lumen, and the periphery (Fig. 2D).

By 1 month there was evidence of the development of ductal adenocarcinoma (Fig. 2E). Enlarged lumens frequently contained cell debris and inflammatory cells. Heterogeneous cells surrounding enlarged lumens were continuous with cells that invaded the surrounding connective tissue. Evaluation of histologic sections from animals implanted with DMBA for 1 to 4 months revealed pancreatic cancer in $70 \%$. The cancer developed close to the implanted DMBA, usually within a nodule composed in large part of desmoplastic reaction.

\section{Continuing Tubular Complex Formation}

Although adenocarcinoma developed from some tubules at 1 month, the process of tubular complex formation continued. Lobules continued to undergo transition to tubular complexes (Fig. 2G). Chymotrypsin in the transitional stages indicated the continuing participation of acinar cells in the process.

Double-staining for chymotrypsin and cytokeratin (Fig. 2, $\mathrm{F}$ and $\mathrm{H}$ ) verified continuing transition as part of the process of tubular complex formation. Chymotrypsin commonly was completely lost, with subsequent appearance of cytokeratin (Fig. 2F). However, examples of cells positive for both chymotrypsin and cytokeratin also were present (Fig. 2H).

The location of DMBA was detected by the negative image of crystals surrounded by extracellular matrix (Fig. 1A). The carcinogen persisted in the tissue, so its effect was long-lasting. It was detected in animals for the duration of the study.

Chronic inflammatory cells became prominent with time. At 1 month, lymphocytes were dominant. Massive chronic inflammation was detected in some animals by 3 months.

\section{Entry into the Cell Cycle}

Assessment of the entry of duct cells into the cell cycle revealed a single, transient peak on the second day after implantation of DMBA (Fig. 3). The fraction of cells labeled with $\mathrm{Ki} 67$ in the tubular complexes remained at a low level at 4 days and 1 week, and then increased at 1 and 3 months (Fig. 3). The appearance of the peak at 2 days led us to quantify mitotic figures at 2 and 4 days after implantation to determine if cells were dividing at more than a minimal rate. One thousand nuclei were counted in ducts on Days 2 and 4, 


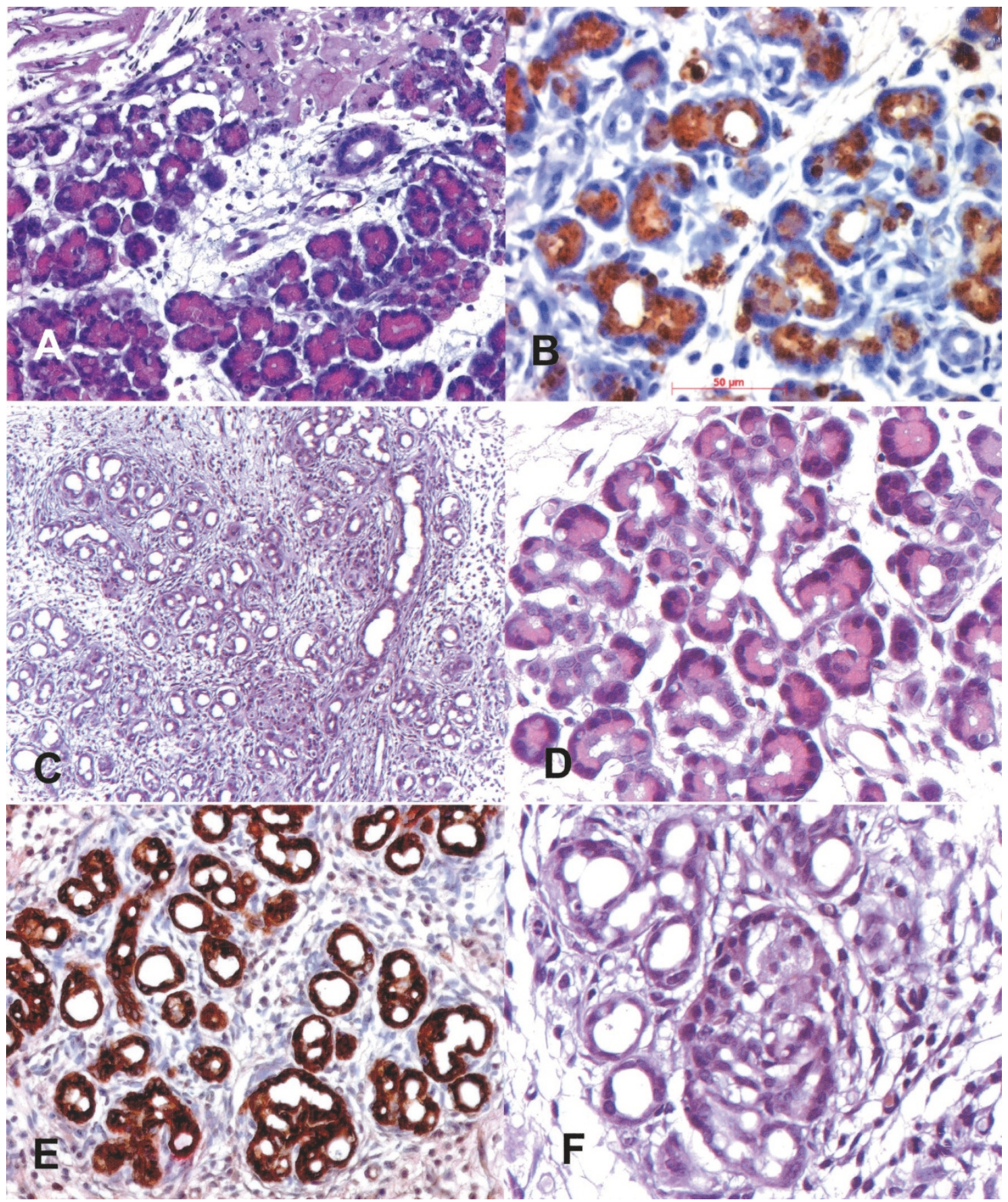

Figure 1.

Histologic sections of pancreas 1,2, and 4 days following implantation of carcinogen (dimethylbenzanthracene; DMBA). (A) One day after implantation. Negative images of elongate DMBA crystals are in the top-left corner. Necrotic cells occupy the top center. Acini are separated by edema $(H \& E$, original magnification $\times 180)$. (B) Two days after implantation. Chymotrypsin localization (brown reaction product) identifies acinar cells. Enlarged lumens are evident in some acini as the transition to ductular structures begins (hematoxylin counterstain, original magnification $\times 360$ ). (C) By 4 days fully developed tubular complexes are present, maintaining somewhat the architecture of lobules $(H \& E$, original magnification $\times 90)$. (D) Transition from lobules to tubular complexes continues at 4 days after implantation. Acinar cells identifiable by the red color of zymogen granules occupy the periphery of developing tubular structures. The continuity of exocrine tissue is evident $(\mathrm{H} \& \mathrm{E}$, original magnification $\times 360$ ). (E) Double-staining for chymotrypsin (red) and cytokeratin (brown) shows that fully developed tubular complexes possess only the cytokeratin marker for ductular cells. The acinar marker, chymotrypsin, has been lost (hematoxylin counterstaining, original magnification $\times 180$ ). (F) Four days after implantation of DMBA, an islet (center) participates in the transition to tubular structures. Adjacent tubular structures have a larger lumen and a thinner wall than the early transition stage in $\mathrm{D}(\mathrm{H}$ \& $\mathrm{E}$, original magnification $\times 360)$.

and in tubular complexes on Day 4. Means of 6.3 and 1.3 nuclei per thousand were positive in ducts on Day 2 and Day 4, respectively. A mean of 3.3 nuclei per thousand was positive in tubular complexes on Day 4.

\section{Tubular Complexes in Controls}

Tubular complexes developed in controls implanted with sodium chloride crystals and in shams (not shown) in 


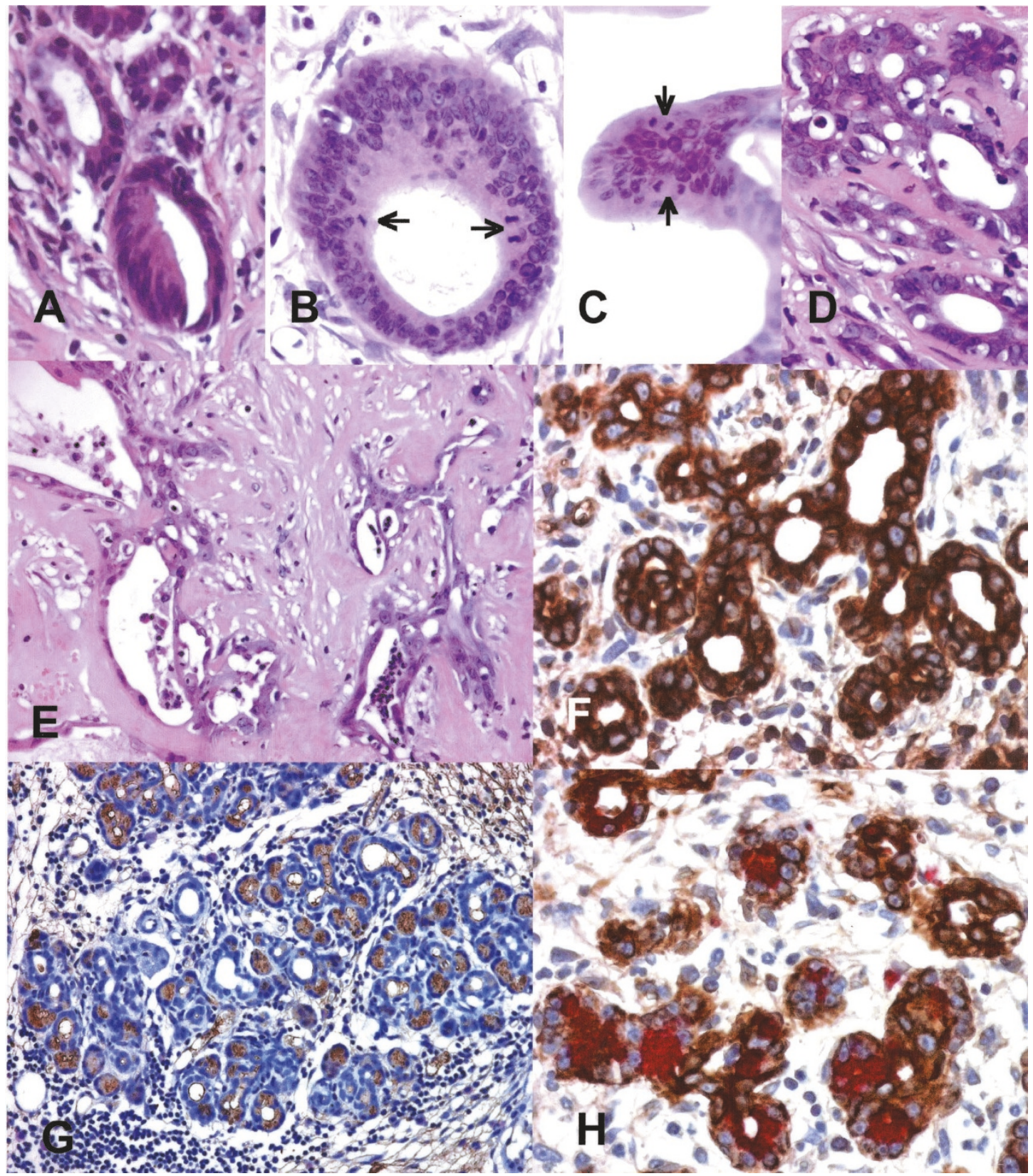

Figure 2.

Histologic sections of pancreas 2 weeks and 1 month after implantation of carcinogen. (A) Cells in a tubule have become elongate rather than cuboidal 1 month after implantation $(\mathrm{H} \& \mathrm{E}$, original magnification $\times 360)$. (B) The wall of a tubule has become multilayered (arrows indicate mitotic figures) 2 weeks after implantation ( $\mathrm{H}$ \& $\mathrm{E}$, original magnification $\times 360)$. (C) Arrows indicate mitotic figures in a papillary structure 2 weeks after implantation (H \& E, original magnification $\times 360)$. (D) The homogeneous arrangement of a simple layer of cuboidal cells to form the wall of each tubule in tubular complexes has become distorted as irregular epithelial cells are produced 1 month after implantation $(H \& E$, original magnification $\times 360)$. (E) Ductal adenocarcinoma has developed 1 month after implantation. Epithelial cells invading the connective tissue matrix are irregular and atypical $(\mathrm{H} \& \mathrm{E}$, original magnification $\times 180)$. ( $F)$ Two weeks after implantation, the continuity of tubular structures in the tubular complex is obvious. Double-staining for chymotrypsin and cytokeratin reveals that transition to the ductular marker cytokeratin is complete only brown reaction product, indicating cytokeratin, is evident (hematoxylin counterstain, original magnification $\times 360$ ). (G) Although most tubular complexes are mature, new ones also are being formed 1 month after DMBA implantation. Localization of chymotrypsin (brown reaction product) reveals the acinar cells yet to transdifferentiate to ductular cells (hematoxylin counterstain, original magnification $\times 90)$. (H) Double-staining of this specimen 2 weeks after implantation shows both chymotrypsin (red) and cytokeratin (brown) in this transitional tubular complex (hematoxylin counterstain, original magnification $\times 360$ ).

parallel with animals implanted with DMBA. However, transition of lobules to tubular complexes did not continue as it did for the DMBA-implanted animals, and the tubular complexes did not transform into cancer. A transient peak in the percentage of Ki-67-positive cells was observed in controls, but at a lower level than in DMBA-implanted animals. By 3 and 4 months, tubular complexes were rare or nonexistent in controls, even in the region of the pancreas where sutures marked the site of original trauma.

\section{Discussion}

This study provides direct and clear evidence of incorporation of acinar cells and islet cells into tubular 


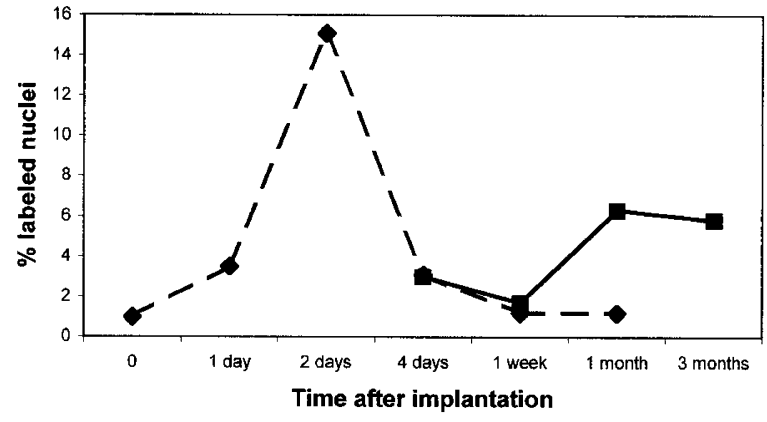

Figure 3.

A transient peak of labeling for Ki-67, an indication of entry into the cell cycle, occurred in the nuclei of duct cells (dashed line) 2 days after DMBA implantation. Labeling in cells in the tubular complexes (solid line) began at the same level as duct cell nuclei, and then increased during the periods when proliferation was occurring (1 and 3 months).

complexes. Well-developed tubular complexes have the morphology and markers of duct cells. Some of the cells in the tubular complexes transformed into cancer cells in the presence of carcinogen. The cells that transformed, therefore, may at one time have been acinar cells and islet cells. In addition, duct cells that were present before DMBA implantation and were incorporated into the tubular complexes would be subject to transformation.

Since the suggestion that acinar cells should be included in the origin of experimental pancreatic cancer induced by DMBA (Bockman et al, 1978), ample evidence has accumulated that pancreatic epithelial cells exhibit a plasticity, which is manifest in their ability to change from one phenotype to another. These transitions are observed in vivo and in vitro.

\section{Transdifferentiation of Acinar Cells to Duct Cells}

In vitro studies of human and animal acinar preparations have shown the transition of acinar cells to duct-like cells (Arias and Bendayan, 1993; DeLisle and Logsdon, 1990; Hall and Lemoine, 1992; Rooman et al, 2000). The transdifferentiation can be accomplished within 4 days. Rooman et al (Rooman et al, 2000) cultured rat acini and used both morphology and markers to follow the transition. Acinar cells transdifferentiated directly into duct cells without dividing. The cells lost their acinar phenotype and then started expressing cytokeratins.

A transition similar to that in the current study has been demonstrated in transgenic mice that overexpress TGF- $\alpha$. Acini in the pancreas of these mice undergo transdifferentiation to duct-like cells, forming tubular complexes, which represent premalignant lesions. Some of the duct-like cells undergo malignant transformation with increased age (Wagner et al, 1998). Cross-breeding these mice with p53-null mice enhances tumor development, producing a model that recapitulates the pathomorphologic features and genetic alterations of the human disease (Wagner et al, 2001). Activation of Ras is detected in the transgenic mice. K-ras mutations are frequent in cancer pro- duced in rats implanted with DMBA (Z'graggen et al, 2001).

In preliminary experiments, evidence of direct acinar-to-duct transdifferentiation has been produced using mice in which cells producing elastase (acinar cells) express a lacZ reporter gene. Adding TGF- $\alpha$ to mouse pancreatic acini suspended in collagen gels leads to expansion of duct-like epithelium similar to the tubular complexes induced by in vivo overexpression of TGF- $\alpha$. Virtually all of the duct epithelium produced in this way demonstrated strong lac $Z$ activity, consistent with duct epithelium deriving directly from acinar cells (Leach SD, personal communication).

The activity of substances driven by elastase promoters, as in mice overexpressing TGF- $\alpha$ and those with the lacZ reporter, would be expected to affect acinar cells. It is perhaps significant that, in the current study, similar changes in acinar cells result from the administration of a substance (DMBA) that is not dependent on a characteristic of any particular kind of cell for its effect.

\section{Transdifferentiation of Islet Cells}

Considerable evidence indicates that islet cells can undergo transdifferentiation to duct cells. Transition of islet cells to duct cells in long-term culture has been reported (Schmied et al, 2001). Isolated human pancreatic islets embedded in type-1 collagen gel in the presence of a defined medium undergo transdifferentiation to duct epithelial structures (Yuan et al, 1996). For this process to proceed, cAMP-mediated signal transduction and an appropriate integrin-matrix interaction are necessary (Wang et al, 2001). Transition to ducts occurs within 4 days, similar to the timing in the present study. Solid islets become cyst-like structures composed of duct cells as defined by morphology and expression of cytokeratin.

\section{Entry into the Cell Cycle}

The presence of Ki-67 in nuclei was used to identify cells that had entered the cell cycle. Ki-67 is not present in G0. It appears in mid-G1 and is expressed until mitosis (Scholzen and Gerdess, 2000). It differs, therefore, from a marker such as BrdU, which is incorporated into the DNA during the $S$ phase. The cells that are positive for Ki-67 do not necessarily divide (Trivedi et al, 2001). Unless they make it through the check-points, synthesize new DNA, and undergo mitosis, they will not complete the cell cycle. The appearance of the peak of Ki-67-positive nuclei on Day 2 led us to quantify mitoses because of the distinct impression of the scarcity of mitotic figures gained while studying the sections. The quantification supported our impression: the number of mitotic figures was minimal. The seeming discrepancy of the Ki-67 peak at Day 2 and the paucity of mitoses may find an explanation in the cell death that occurs during this early period. There is ample evidence that cell death is accompanied by re-entry into the cell cycle (Herrup and Busser, 1995). Withdrawal of nerve growth factor from cultured sympathetic neurons causes apoptosis, 
which is accompanied by the induction of cyclin D1, a G1/S phase marker (Freeman et al, 1994). Similarly, cisplatin-induced cell death, in vivo and in vitro, involves re-entry into the cell cycle (Gill and Windebank, 1998). Although apoptosis in the weaver mouse ( $w / / w v)$ is accompanied by marked cell cycle up-regulation, the mitotic index does not change, showing that proliferation is not occurring. Apoptosis could arise from late G1, as shown for $\mathrm{T}$-cell receptor antigen-induced cell death in $\mathrm{T}$ lymphocytes (Lissy et al, 1998), or from S phase, as occurs in $\mathrm{NT}^{-3^{--}}$mice, which lack Neurotrophin-3 (EIShamy et al, 1998). The TGF- $\alpha$ that is overexpressed in transgenic mice promotes progression through $\mathrm{G} 1$ of the cell cycle, but not S phase (Wagner et al, 2001).

In the current study, the parallel of entry into the cell cycle with cell death before mitosis is clear. The presence of mitoses longer after implantation in regions where multiple layers and papillary structures develop is consistent with proliferation resulting from completion of the cell cycle.

\section{Enlargement of Lumens}

Transition of lobules into tubular complexes characteristically includes the enlargement of the lumen of acini. Part of the mechanism probably is due to the loss of zymogen granules reducing the height of acinar cells. Information gained from other studies provides an additional reasonable explanation for lumen enlargement. The ends of pancreatic ducts in culture seal off to create enclosed lumens (Githens et al, 1980). As a result the lumens enlarge and the epithelial cells flatten at the periphery. A similar phenomenon occurs as islets transdifferentiate in vitro (Wang et al, 2001). The enlarged lumens and flattening of epithelial cells in well-developed tubular complexes is interpreted to be in part the result of sealing off of segments of acini and ducts in the original lobules in reaction to injury. In support of this interpretation, three-dimensional reconstruction of a tubular complex revealed that it consisted of three separate parts (Bockman et al, 1978). Each of the three parts was continuous, and one had a cyst-like expansion larger than the diameter of most tubules.

\section{Significance of Transdifferentiation}

Understanding the progression that leads to pancreatic cancer requires distinguishing between two things: (a) ductal adenocarcinoma arising exclusively from duct cells, in which Case one would search for the unique characteristic that would cause only these cells to be transformed, versus (b) ductal adenocarcinoma arising from duct, acinar, and/or islet cells, in which Case one would investigate the conditions causing the first transdifferentiation, followed by the changes that convert these altered cells to cancer.

The findings of the current investigation strongly suggest that the tubular complexes that may be seen in association with pancreatic ductal adenocarcinoma do not represent solely the proliferation of centroacinar cells or duct cells as precursors of cancer. Rather, it is likely that acinar, islet, and duct cells (including centroacinar cells) contribute to the pool of duct cells in tubular complexes, any of which may transform into adenocarcinoma.

Transdifferentiaton is not limited to the effect of DMBA. It is observed after ductal ligation of the normal pancreas (Isaksson et al, 1983; Wang et al, 1995) and in tissue from patients with chronic pancreatitis (Bockman et al, 1982). It occurred as a result of the trauma caused in the control animals in the current study. The application of the current investigation to human pancreatic cancer is uncertain. However, one wonders if the tubular complexes found in chronic pancreatitis (Bockman et al, 1982) contain cells that are genetically altered enough to be more susceptible to carcinogenic influences because they have differentiated to one phenotype only to revert to another in response to nonphysiologic stimuli.

\section{Materials and Methods}

\section{Animals, Implantation, and Harvest}

Male Sprague-Dawley rats weighing 120 to $140 \mathrm{gm}$ were anesthetized with Ketanest and Rompun. The spleen and pancreas were exteriorized through an abdominal incision. A pocket was produced in the tail of the pancreas by gently and incrementally spreading the tissue with microforceps. For initiation of experimental pancreatic cancer, approximately $5 \mathrm{mg}$ of DMBA (9,10-dimethyl-1,2-benzanthracene; Sigma, St. Louis, Missouri) was inserted into the pancreatic pocket by a microspatula. To control for nonspecific tissue trauma, additional animals had approximately 5 mg of sodium chloride crystals implanted into the pocket, or the pocket was closed without implanting anything (shams). The pocket was closed in all animals with 6-0 prolene suture. Experiments were approved by the animal research committee for the university.

Animals were killed at intervals of 1, 2, and 4 days; 1 and 2 weeks; and 1, 3, and 4 months after implantation of DMBA. Pancreatic tissue was fixed in $10 \%$ formalin in phosphate buffered saline for routine paraffin histologic and immunohistochemical techniques. Ten animals were included in the group to be killed at each interval. For each ten animals, six were implanted with DMBA, two with sodium chloride crystals, and two were shams. An exception was the group killed 3 months after implantation; a total of 15 animals originally were included in this group (nine DMBA, three $\mathrm{NaCl}$, and three shams). However, the body weight of one animal (C612) was not increasing in parallel with the others so it was killed 2 months after implantation. An additional three animals were killed without any treatment to provide a baseline in the absence of surgery.

\section{Markers for Cell Types}

Markers for different differentiated cell types included chymotrypsin for acinar cells and cytokeratin for ductular cells. Antibody to chymotrypsin (Clone 4E1) was obtained from Biogenesis Ltd., Poole, England. Anticyto- 
keratin and the Protease XXIV Pretreatment Kit came from DCS Innovative, Hamburg, Germany. The anticytokeratin antibody (AM-2070-11), produced in response to the human carcinoma A431 cell line, is described as reacting with human cytokeratins $4,5,6,8,10,13$, and 18. When tested against unaffected rat pancreas, the antibody localized ductal cells and not acinar cells. Antibody to Ki-67 from Dako (Hamburg, Germany) was used to detect the entry of cells into the cell cycle. Primary antibodies were revealed using the Envision System (Dako), and double-staining was accomplished using the EnVision Doublestain System (Dako) to produce brown reaction product for cytokeratin and red for chymotrypsin. Negative controls prepared by omitting the primary antibody were routinely negative.

\section{References}

Arias AE and Bendayan M (1993). Differentiation of pancreatic acinar cells into duct-like cells in vitro. Lab Invest 69:518-530.

Bockman DE and Merlino G (1992). Cytological changes in the pancreas of transgenic mice overexpressing transforming growth factor $\alpha$. Gastroenterology 103:1883-1892.

Bockman DE, Black O, Mills LR, and Webster PD (1978). Origin of tubular complexes developing during induction of pancreatic carcinoma by 7,12-dimethylbenz(a)anthracene. Am J Pathol 90:645-658.

Bockman DE, Black O, Mills LR, Mainz DL, and Webster PD III (1976). Fine structure of pancreatic adenocarcinoma induced in rats by 7,12 -dimethylbenz[a]anthracene. J Natl Cancer Inst 57:931-936.

Bockman DE, Boydston WR, and Anderson MC (1982). Origin of tubular complexes in human chronic pancreatitis. Am J Surg 144:243-249.

DeLisle RC and Logsdon CD (1990). Pancreatic acinar cells in culture: Expression of acinar and ductal antigens in a growthrelated manner. Eur J Cell Biol 51:64-75.

Dissin J, Mills LR, Mainz DL, Black O Jr., and Webster PD (1975). Experimental induction of pancreatic adenocarcinoma in rats. J Natl Cancer Inst 55:857-864.

EIShamy WM, Fridvall LK, and Ernfors P (1998). Growth arrest failure, G1 restriction point override, and $S$ phase death of sensory precuror cells in the absence of Neurotrophin-3. Neuron 21:1003-1015.

Freeman RS, Estus S, and Johnson EM Jr (1994). Analysis of cell cycle-related gene expression in postmitotic neurons: Selective induction of Cyclin D1 during programmed cell death. Neuron 12:343-355.

Gill JS and Windebank AJ (1998). Cisplatin-induced apoptosis in rat dorsal root ganglion neurons is associated with attempted entry into the cell cycle. J Clin Invest 101:2842-2850.

Githens S III, Holmquist DR, Whelan JF, and Ruby JR (1980). Ducts of the rat pancreas in a agarose matrix culture. In Vitro 16:797-808.

Hall PA and Lemoine NR (1992). Rapid acinar to ductal transdifferentiation in cultured human exocrine pancreas. J Pathol 166:97-103.

Herrup K and Busser JC (1995). The induction of multiple cell cycle events precedes target-related neuronal death. Development 121:2385-2395.
Isaksson G, Ihse I, and Lundquist I (1983). Influence of pancreatic duct ligation on endocrine and exocrine rat pancreas. Acta Physiol Scand 117:281-286.

Jimenez RE, Z'graggen K, Hartwig W, Graeme-Cook F, Warshaw AL, and Fernandez-del Castillo C (1999). Immunohistochemical characterization of pancreatic tumors induced by dimethylbenzanthracene in rats. Am J Pathol 154:12231229.

Lissy NA, Van Dyk LF, Becker-Hapak M, Vocero-Akbani A, Mendler JH, and Dowdy SF (1998). TCR antigen-induced cell death occurs from a late $\mathrm{G} 1$ phase cell cycle check point. Immunity 8:57-65.

Rivera JA, Graeme-Cook F, Werner J, Z'graggen K, Rustgi AK, Rattner DW, Warshaw AL, and Fernandez-del Castillo C (1997). A rat model of pancreatic ductal adenocarcinoma: Targeting chemical carcinogens. Surgery 122:82-90.

Rooman I, Heremans Y, Heimberg H, and Bouwens L (2000). Modulation of rat pancreatic acinoductal transdifferentiation and expression of PDX-1 in vitro. Diabetologia 43:907-914.

Sandgren EP, Luetteke NC, Palmiter RD, Brinster RL, and Lee DC (1990). Overexpression of TGF $\alpha$ in transgenic mice: Induction of epithelial hyperplasia, pancreatic metaplasia, and carcinoma of the breast. Cell 61:1121-1135.

Schmied BM, Matsuzaki A, Ding H, Ding X, Ricordi C, Weide L, Moyer MP, Batra SK, Adrian TE, and Pour PM (2001). Transdifferentiation of human islet cells in a long-term culture. Pancreas 23:157-171.

Scholzen T and Gerdess J (2000). The Ki-67 protein: From the known and the unknown. J Cell Physiol 182:311-322.

Trivedi N, Hollister-Lock J, Lopez-Avalos MD, O'Neil JJ, Keegan M, Bonner-Weir S, and Weir GC (2001). Increase in $\beta$-cell mass in transplanted porcine neonatal pancreatic cell clusters is due to proliferation of $\beta$-cells and differentiation of duct cells. Endocrinology 142:2115-2122.

Wagner M, Greten FR, Weber CK, Koschnick S, Mattfeldt T, Deppert W, Kern H, Adler G, and Schmid RM (2001). A murine tumor progression model for pancreatic cancer recapitulating the genetic alterations of the human disease. Genes Develop 15:286-293.

Wagner M, Lührs H, Klöel G, Adler G, and Schmid RM (1998). Malignant transformation of duct-like cells originating from acini in transforming growth factor transgenic mice. Gastroenterology 115:1254-1262.

Wang R, Li J, and Rosenberg L (2001). Factors mediating the transdifferentiation of islets of Langerhans to duct epitheliallike structures. J Endocrinol 171:309-318.

Wang RN, Kloppel G, and Bouwens L (1995). Duct- to islet-cell differentiation and islet growth in the pancreas of duct-ligated adult rats. Diabetologia 38:1405-1411.

Yuan S, Rosenberg L, Paraskevas S, Agapitos D, and Duguid WP (1996). Transdifferentiation of human islets to pancreatic ductal cells in collagen matrix culture. Differentiation 61:67-75.

Z'graggen K, Warshaw AL, Werner J, Graeme-Cook F, Jimenez RE, and Fernandez-del Castillo C (2001). Promoting effect of a high-fat/high-protein diet in DMBA-induced ductal pancreatic cancer in rats. Ann Surg 233:688-695. 